\title{
Study of Practical Personnel Training based on the Integration of Professional Education and Innovation Education
}

\author{
Ping Wang ${ }^{1, \text { a }}$ \\ ${ }^{1}$ Nanchang Institute of Science \&Technology, Nanchang, Jiangxi, 330108 \\ ${ }^{\mathrm{a}}$ email
}

Keywords: Practical Personnel Training, Professional Education, Innovation Education

\begin{abstract}
Entrepreneurship education is a new concept of the new era of higher education, higher education has become the object of new values, the present era is the need of training college students' creativity and creative ability, talent demand is changing the social and economic structure adjustment period requirements, the quality of higher education to train personnel to deepen an important initiative! philosophy will permeate entrepreneurship education integrated into the process of professional education to help students in the contemporary professional education teaching process actively foster a sense of entrepreneurship, Students' entrepreneurial spirit, improve college students knowledge of the structure of great significance.
\end{abstract}

\section{Introduction}

Training Students' Ability of innovation and entrepreneurship, higher education is socially oriented market economy, an important measure of school. In recent years, the party and the country attaches great importance to innovation and entrepreneurship students education, the Ministry of Education has launched the "Students' Innovation and Entrepreneurship Training Program", "Training Students model innovation pilot area" and other projects in order to promote innovation, entrepreneurship and management of high-level personnel to cultivate. To this end, our biology, pharmacy, medicine, chemistry, engineering and other advantages of interdisciplinary resources as the basis for curriculum reform and personnel training program of reform as the key to innovation and entrepreneurship training mechanism for guidance, to develop biological drug development, the transformation and entrepreneurship, management of high-end talent as the goal, innovation and entrepreneurship education concepts into undergraduate training programs, innovation and entrepreneurship education into the curriculum and professional practice into teaching, strengthen the integration of professional education and innovation and entrepreneurship education in order to build biology and pharmacy interdisciplinary research and application of combined teaching entrepreneurship and innovation content convergence a new system to enhance the innovative ability students, employment competitiveness and sustainable development potential. 2014 "The New Model of Higher Learning and Social Education Collaborative Practice" selected Higher National Teaching Achievement Award candidate projects.

\section{Value Analysis of Innovation Education and Professional Education}

Organic as two integral part of higher education, creating two education and professional education are inseparable, interrelated and mutual penetration, complementary and mutually reinforcing goals consistent with both orientations, all with high-quality training to adapt to economic and social development of qualified talent as a fundamental task of both the nature of the contents of the same, the same as the relationship between creative education and professional education determines the function of the two are merging innovative Education and common development must not be divorced from professional education and in isolation, it is not separated from the professional education outside skills training activities, but resides in professional education training program, including theoretical and practical teaching in the whole process of teaching concept and mode, it; emphasizes professional anchored reinforce professional basis, a professional advantage $<\mathrm{F}$ Thus, professional education is the starting point and basis for innovative education, education is the use 
of two hit and deepen professional education and Universities in China at present two creators education is not really into the professional education system, resulting in two hit only stay in some kind of education and skills operational level, still remain in the minority; entrepreneurial activity, rather than the majority of people; on the level of entrepreneurship education to change this situation, we must go out of misunderstanding innovative education professional education, the two create awareness and capacity as the culture of higher education target, Colleges into the overall training program, so that the spirit of innovation Students. Entrepreneurship Awareness and entrepreneurial ability to get rooted in professional education. This is the inevitable choice for the development of higher education, with the necessity and urgency.

\section{Entrepreneurship Education Problems}

The basic content of entrepreneurship education is to develop and improve students' entrepreneurial qualities that students of professionalism\% initiative, pioneering spirit, the spirit of innovation, as well as engaged in a cause, business, business planning skills and psychological quality education activities. currently, entrepreneurship education in Chinese universities mostly around how to start a series of quality and ability of enterprise and entrepreneurship needs carried out. entrepreneurship education there are four aspects First, entrepreneurship education \& employment only as an integral part of education. many entrepreneurial education in universities still remain in terms of skill, psychology, policy, situation analysis, guidance, the students deep sense of entrepreneurship\%, entrepreneurship education and entrepreneurial capacity has not yet attracted attention, no systematic education system.

Second, entrepreneurship education in all types of entrepreneurial activity mainly present entrepreneurship education in universities mainly in the form of the Communist Youth League organizations and the student body set up by management to entrepreneurship lectures, business plan competitions and associations and other extracurricular activities expanded, however, these only a few people attended the event, and the effect of education is not ideal.

Third, entrepreneurship education will simply be positioned as a business owner intensive education (colleges and universities currently in the business part of our practice simple guide students to set up large and small student start-up companies (but by no means is an entrepreneurship education can be short-term intensive education. US Best Sen Business School professor Timmons told the American Enterprise Education utilitarian tendency appears commented: the way encourage entrepreneurs to create so-called, in order to create high-tech industry can not meet the needs of entrepreneurs as a symbol of the revolution.

Fourth, entrepreneurship education and professional education out of touch. Entrepreneurship education process undertaken by many colleges and universities, will be unable to start the basics, the basic quality of the same culture organically combine professional education, entrepreneurship education will also failed to penetrate into the whole process of professional, although some colleges and universities opened with entrepreneurship education-related courses, but entrepreneurship education has not been integrated into the teaching system in general.

\section{Relationship between Entrepreneurial Education and Professional Education}

Entrepreneurship education is a high socio-economic development, while facing labor employment, re-employment under the enormous pressure of the background, and promote the development of an educational model, which is the general trend of the world development of higher education, but also the necessity of reform and development of higher education ! Select entrepreneurship education as the history of higher education to develop a new philosophy of education, academia is currently a hot topic of intense debate on entrepreneurship education connotation understanding, there are three more representative views: the first view is that entrepreneurship education is education, training objectives of entrepreneurship education and vocational education to create a combination of education is based on modern principles of education, training in certain occupations have the ability to work and ability to adapt to social life of people; second view is that 
entrepreneurship education is Training groundbreaking personal education, which aims to provide students a flexible, sustainable and lay the foundation for lifelong learning; third view is that entrepreneurship education means to develop and improve the basic quality of university students entrepreneurship targeted by College students in business, corporate, commercial and other plans, activities, processes, education and ambitious, enterprising spirit of exploration, adventure and other psychological quality education to train students have engaged in entrepreneurial practice to groundbreaking education! While the above views expressed are not First, we find that its common: entrepreneurship education is to cultivate entrepreneurship education goals is to educate students on how to embark on the community, so that students self-entrepreneurial spirit and skills through entrepreneurship education, self-development capabilities and method and actively adapt to the concept of employment and social psychological quality.

\section{Innovative Education and Professional Education Integration Path Selection}

Fusion path seek innovative education and professional education and to strengthen the integration, we must establish professional education and creative education in one of the philosophy of education, philosophy of education only do both fusion, in order to achieve the coordination of professional education and innovative teaching time, to education The goal. First, we must change the concept of a single professional education to fully understand the importance of innovation education. Innovative education is to train entrepreneurial talents as the goal of education is to teach students how to embark on the community, so that students self-entrepreneurial spirit, skills, abilities and self-development through innovative education initiative to adapt the concept of employment and social psychological quality. Professional education and career with the disciplines differentiation differentiation generated, it is instrumental to meet people or social and practical needs. Professional education aimed at imparting knowledge and professional skills training for students to participate in social production as soon as possible to prepare for practice.

Secondly, we need a deep understanding of the dialectical relationship between creative education and professional education, establish the integration of both educational philosophy. Innovative education is not new content outside professional education, professional education but deepening and concrete, is the era of the times and the requirements of professional education content. Innovative educational philosophy permeate, integrated into the process of professional education for contemporary college students to help establish a positive sense of entrepreneurship to train students' entrepreneurial spirit, improve the knowledge structure of college students is significant.

Since more and more the overall quality of vocational employer's attention, we should focus on training and Two Students Practical Ability. To achieve this goal, we should practice teaching and Innovation Education combat training professional education organically integrate that promote mutual interpenetration between them.

First, the school should be combined with professional education resources and actively develop high feasibility of creating two projects to expand the project to create two college students practice and provides specific entrepreneurial planning program for each project and guide the students to create two practices. Secondly, through the organization of entrepreneurship forum entrepreneurship competition Venture construction sites and other forms of extracurricular entrepreneurial activities to promote communication and exchange students entrepreneurial groups. Again, inside and outside the school to strengthen the entrepreneurial base construction for college students to build incubation platform, start a business or to help students master the business management knowledge, enrich students' learning and practice of entrepreneurship, innovation and expand educational function Colleges. Of course, the entrepreneurial base construction related to all aspects alone the power of colleges and universities is not enough, we need to attach great importance to the whole society. Schools and local governments should be based on the characteristics of college students, and to give preferential policy support. Only create a good social environment and improve the overall effect, in order to create more opportunities to practice two creators.

Innovative education and professional education is an integral part of the activities of higher 
education, the purpose is to train high-quality talents with innovative spirit and entrepreneurial ability. There is no absolute creative education and professional education division, professional education is the foundation, innovation is the practice of education, although the two can not replace each other, but can be integrated with each each other. We need to create two education and professional education combine in a comprehensive professional education of penetrating innovation education, strengthening students' professional knowledge base and improve the overall quality of students and the two hit capability. Integration of innovative education and professional education, higher education is a requirement for progress and development, we are working together to promote high-level personnel training an important measure, but also the inevitable choice of higher education reform.

\section{Conclusion}

The introduction of entrepreneurship education to professional education, is not a simple sum of the two, but so that the two link up effectively to integrate knowledge of organic content, highlight and penetration entrepreneurship education in professional education, the realization of entrepreneurship education sustainable development.

\section{Acknowledgements}

12015 Annual College of Humanities and social science research projects in Jiangxi Province Educational System of Applied Undergraduate innovation and entrepreneurship - A XX university as an example (JY1571).

2015 Annual Nanchang Institute of Science \& Technology teaching reform project "training based on application-oriented talents innovation and entrepreneurship. Nanchang Institute of Science \& Technology Case "- and implementation way of educational system.

\section{References}

[1] Willams, K. D., Nida, S. A., Baca, L. D., Latane, B. Social loafing and swimming: Effects of identifiability on individual and relay performance of intercollegiate swimmers [J]. Basic and Applied Social Psychology, 1998, (10):73-8].

[2] Dess, Lumpkin, Covin. Entrepreneurial strategy making and firm performance test of contingency and configurational models [J].Strategic Management journal,2007, 18(9): 677-695.

[3] Judith. Jeffrey, John, et al. Entrepreneurial Teams in New Venture Creation: A Research Agenda [J]. Entrepreneurship Theory and Practice, 2004.33-47,

[4] Timmons. J.A. New Venture Creation [M].l n: Mc Cn'awHil, 1999.

[5] Ballou, R. Bowers, D., Boyatzis, R. E., and Kolb, D.A. Fellowship in lifelong learning: Anexecutive development program for advanced professionals [J]. Journal of Management Education, 2002, 23(4):338-354.

[6] Baum. JR.The relationship of traits,competencies, motivation, strategy and structure to venture growth [D]. Ph.D. Dissertation, University of Maryland, USA, 2004, 135-157.

[7] Alex\&erardieh A theory of entrepreneurial opportunity identification and development [J]. Journal of Business Venturing, 2003, (18); 105-123. 